\title{
Determination of hepatoprotective and antioxidant role of thyme (origanum onites l.) infusion against ethyl alcohol induced oxidative stress in rats
}

\author{
Shreen Musa ${ }^{(D)}$, İsmail Çelik* (D) \\ Van Yüzüncü Yıl University, Department of Molecular Biology and Genetics, TR-65080, Van, Turkey
}

\section{ART I CLE INFO}

\section{Article history:}

Received 09 Jun 2020

Received in revised form 07 October 2020

Accepted 17 November 2020

Keywords:

Origanum onites

Antioxidant

Hepatoprotective

\begin{abstract}
A B S T RACT
In this study, we aimed to determine the hepatoprotective and antioxidants role of thyme $(O$. onites $)$ against ethyl alcohol (EtOH) induced oxidative stress in rats. The experiment conducted as control, $20 \%$ $\mathrm{EtOH}, 3 \% O$. onites infusion and $3 \%$ O. onites $+20 \% \mathrm{EtOH}$ groups. The antioxidant and hepatoprotective role of $O$. onites infusion was evaluated by histopathological chance and serum damage biomarkers of liver (LDB), antioxidant constituents (ACs) and malondialdehyde (MDA). According to results, Liver damage serum enzymes activities were significantly higher in $20 \% \mathrm{EtOH}$ group compared to normal control (NC) whereas the parameters were significantly lower in the infusion supplemented groups compared to $20 \% \mathrm{EtOH}$ group. Also, MDA content of $20 \% \mathrm{EtOH}$ group increased significantly in all tissues compared to $\mathrm{NC}$ group but decreased as comparison with $20 \% \mathrm{EtOH}$. The results suggest that the infusion restored the most of the parameters towards the $\mathrm{NC}$ with fluctuations in the ACs.
\end{abstract}

\section{Introduction}

Today, humankind have been using the plants, herbs, and ethnobotanicals from the early stages and are still used everywhere around the world for the treatment of diseases and health improvement. Today's modern medicine is established on plant and natural sources and they take a large part in today's commercial drug development and manufacture. Nearly $25 \%$ of the prescribed medications around the world are obtained from plants. Even so herbs are commonly used in health care instead of medications. In addition, herbs are used in the treatment of acute and chronic diseases and problems like depression, prostate problems, heart diseases, inflammation and improving the immune system, and a lot of other conditions [1].
There is a copious amount of various compounds in plants a lot of these compounds are secondary metabolites including aromatic compounds and majority of them are phenols and oxygen-substituted derivatives like tannins and a lot of these compounds have antioxidant capacity $[2,3]$. In drug development and pharmacological research ethnobotanicals are significant not just when plant components are directly used as therapeutic agents but also during drug synthesis as a starting material or as models for pharmacologically active compounds [4]. Also, plants and herbs can be handled and taken in various form and ways and these comprise teas, essential oil, whole herb, syrup, salves, ointment, rubs, capsules and tablets having powdered or ground form of the raw herb or its dried extract [1] .Natural antioxidants are thought of to be helpful agents for the hindrance of diseases. Many investigations have stated

\footnotetext{
* Corresponding author. Tel.: +0 432225 1127; fax: +0 4322251514

E-mail address: : icelik@yyu.edu.tr

ORCID : 0000-0002-5314-7212
} 
that the phenolic constituents in the essential oil of plants have antioxidant activity as a result of their ability to scavenge free radicals. In addition, it has been shown that there is a high amount of phenolic constituents in the essential oil of various species of origanum [5].

In the last two decades years, many Origanum species are characterized by different main components. The contents of essential oil of oregano include carvacrol and/or thymol as the major constituents [6-17] and other minor components such as p-cymene, c-terpinene, terpinen-4-ol, linalool, sabinene hydrate, and terpinen-4-ol [15]. Also, in a current study, b-bisabolene, eucalyptol, borneol and other three of the presently unknown constituents from minor compounds are pointed out as aroma impact factors of $O$. onites. Carvacrol and thymol are the main factors of the biological activity of oregano and carvacrol has a lot of pharmacological activities [5]. On the other hands, it have reported that carvacrol has a lot of biological effects containing lipid peroxidase inhibition, antifungal, white blood cell macrophage stimulant, antibacterial, acetylcholine esterase inhibition, cardiac depressant activity and radical scavenging effect and the preservation of food due to their antioxidant properties [18].

In this study, we determined the healing effects of $O$. onites infusion against EtOH-induced hepatotoxicity and oxidative stress in rats evaluated by histopathological change, LDB, ACs and MDA. With this aim, O. onites infusion was given orally as beverage because the plants are well characterized in the healing effects.

\section{Materials and Methods}

\subsection{Animals}

Twenty eight Wistar albino female rats aged 3-4 months and weighing between 150-250 gr were provided by the Van Yüzüncü Yll University Experimental Animal Research Centre. The rats were divided into 4 groups containing 7 rats. The authors decelerate that they have followed EU standards regulations for the protection of animals during experiment and approved by The Local Ethics Committee of Experimental Animal with the protocol number 2018/4.

\subsection{Preparation of Foods}

The plant material was provided from medical and aromatic plants garden of Van Yüzüncü Yıl University, Faculty of Agriculture Field Crops Department. Briefly for the 0 . onites infusion, we weighted 3 grams of $O$. onites for each $100 \mathrm{~mL}$ of water and then we poured the boiling tap water to the plant and let it brew for 15-20 minutes. After that, the mixture was filtered and putted aside to cool. For the 20\% Ethyl alchol mixture, we measured $20 \mathrm{~mL}$ of Ethyl alchol and added $80 \mathrm{~mL}$ of tab water to it and then we shaked it gently and putted it aside. For the 0 . onites + EtOH mixture, we poured $80 \mathrm{~mL}$ of boiling tap water to 3 grams of 0 . onites and let it brew for 1520 minutes. After that, the mixture was filtered and $20 \mathrm{~mL}$ of EtOH was added to it and putted aside to cool. All of these mixtures were prepared as brewed daily and freshly and the bottle sterilized as daily against contamination.

\subsection{Experimental Design}

28 rats used in this study were divided into 4 groups of randomly selected 7 rats in each group:

Group I (Control): Nothing was applied to this group; it was fed only with standard rat feed and water as ad libitum.

Group II (EtOH): The group rats were received 20\% ethanol and fed with standard rat feed. The ethanol dose was chosen based on the fact that $20 \%$ concentration caused oxidative stress orally as ad libitum $[19,20]$.

Group III (\%3 O. onites infusion): This group was given standard rat feed and freshly brewed and chilled $3 \%$ O. onites infusion as ad libitum.

Group IV (\%3 O. onites $+20 \%$ EtOH ) : This group was given standard feed and a mixture of $3 \%$ O. onites and $20 \% \mathrm{EtOH}$ as ad libitum.

\subsection{Preparation of tissues supernatant and erythrocyte pellets}

The rats were anesthetized intra-peritoneally by ketamine ( 5 $\mathrm{mg} / 100 \mathrm{~g}$ body weight) at the end of the designated experimental period. The intracardiac blood was taken from their hearts with the help of injectors for the determination of serum biomarkers and biochemical analysis. For tis purpose, a part of the taken blood in the biochemistry tubes and was centrifugated at $4000 \mathrm{xg}$ for $15 \mathrm{~min}$ at $4{ }^{\circ} \mathrm{C}$. The remaining part used for the preparation erythrocyte pellets put into EDTA tubes. Then, the blood samples were centrifuged at $4000 \times$ g for $15 \mathrm{~min}$ at $4^{\circ} \mathrm{C}$ and then these pellets were washed three times with physiological saline.

After the dissection of the liver and kidney tissues, the tissues were transferred to petri dishes and then the tissues were washed with $0.9 \% \mathrm{NaCl}$ solution and then the samples were preserved at $-78{ }^{\circ} \mathrm{C}$ until the time of analysis. After the addition of $50 \mathrm{mM}$ ice-cold $\mathrm{KH}_{2} \mathrm{PO}_{4}(1: 5 \mathrm{w} / \mathrm{v})$ solution the tissues were homogenised for $5 \mathrm{~min}$ using stainless steel probe homogenizer $(20 \mathrm{KHz}$ frequency ultrasonic, Jencons Scientific Co.) Then, the obtained mixture was centrifuged at $7000 \mathrm{xg}$ for $15 \mathrm{~min}$. All of these processes were carried out at $4{ }^{\circ} \mathrm{C}$. The obtained erythrocyte pellets and Supernatants were used for the determination of MDA contents and ADS constituents [21-23].

\subsection{Biochemical analysis}

This is based on TBA reactivity, the tissue and erythrocyte 
MDA concentration was determined using the technique reported by Jain et al [24]. The measurement of tissue and erythrocyte reduced glutathione (GSH) concentration was made according to the technique reported by Beutler et al [25]. Glutathione $S$-transferase (GST) assay was carried on as stated by Mannervik and Guthenberg [26] method based on the conjugation of glutathione with 1-chloro-2,4dinitrobenzene (CDNB) at $340 \mathrm{~nm}$. Glutathione reductase (GR) assay was carried on as stated by Carlberg and Mannervik [27] method as based on the diminishing in the NADPH absorbance at $340 \mathrm{~nm}$. Glutathione peroxidase (GPx) assay was carried on as stated by Paglia and Valentine [28] method based on that of GPx catalyses the oxidation of GSH. Superoxide dismutase (SOD) assay was made according to McCord and Fridovich method [29] based on the calculation of inhibition percentage of formazan dye formation at $505 \mathrm{~nm}$. Catalase (CAT) assay was made according to Aebi [30] method based on the consumption of $\mathrm{H}_{2} \mathrm{O}_{2}$ at $37{ }^{\circ} \mathrm{C}$ and 240 nm.

\subsection{Measurement of serum biomarkers}

Serum biomarkers related to liver damage such as aspartate aminotransferase (AST), alanine aminotransferase (ALT) enzyme activities and total protein (TP) and total cholesterol (TC) levels were via commercial kits (DPC; Diagnostic Products Corporation, USA) using autoanalyzer (INTEGRA-800 ROCHE).

\subsection{Histopathological examination}

Liver tissue samples were taken and fixated in $10 \%$ buffered formalin solution solution. The routine tissue follow-up and the samples were embedded into paraffin blocks. Then, $4 \mu \mathrm{m}$-sections were taken using microtome (Leica RM 2135) and stained with hematoxylin-eosin [31]. After, the preparation sections examined under light microscope (Nikon 80i-DS-RI2) equipped with a video camera (DXM1200F, Nikon, Tokyo, Japan).

\subsection{Analysis of data}

Minitab 13 for windows packet program was used for the statistical analysis and all the data were expressed as mean \pm standard deviation (SD). For the determination of the differences between means of the experimental groups oneway analysis of variance (ANOVA) statistical test were used and accepting the significance level at $p \leq 0.05$.

\section{Results}

\subsection{Effect of the 0 . onites infusion on food, liquid intake and liver serum biomarkers}

At the end of 30 day experiment, liver damage biomarkers in serum such as AST, ALT activities, TP and TC levels were determined as an indicator of hepatoprotective effects of $O$. onites infusion against EtOH induced oxidative stress in rats. According to the results liver damage serum enzymes activities were significantly higher in EtOH group compared to normal control (NC) whereas the parameters were significantly lower in the infusion supplemented groups compared to EtOH group. As shown in Table 1, the food intake is not change, whereas the fluids consumption of EtOH and alcohol-thyme groups decreased during experimental period compared to that of the control group.

Table 1. Determination of hepatoprotective capacity of Origanum onites L. infusion against ethanol exposed rats

\begin{tabular}{lllll}
\hline & \multicolumn{4}{c}{ Groups } \\
\cline { 2 - 5 } Parameters & Group I & Group II & Group III & Group IV \\
\hline $\begin{array}{l}\text { Food intake } \\
\text { (g/week) }\end{array}$ & $281 \pm 11$ & $310 \pm 16$ & $280 \pm 24$ & $316 \pm 3$ \\
Water intake & & & \\
(mL/week) & $236 \pm 19$ & $121.4 \pm 15^{\mathrm{a}}$ & $247.6 \pm 115$ & $101.9 \pm 3^{\mathrm{a}}$ \\
AST (U/L) & $129 \pm 7.5$ & $140 \pm 12^{\mathrm{a}}$ & $108 \pm 13^{\mathrm{a}}$ & $113 \pm 9^{\mathrm{a}, \mathrm{b}}$ \\
ALT (U/L) & $36 \pm 6$ & $45 \pm 8.2^{\mathrm{a}}$ & $39.6 \pm 5$ & $47 \pm 6.0^{\mathrm{a}}$ \\
TP (g/dL) & $72 \pm 3$ & $64 \pm 3.4^{\mathrm{a}}$ & $69.9 \pm 3$ & $68 \pm 3.8^{\mathrm{a}}$ \\
TC (mg/dL) & $69 \pm 6$ & $45 \pm 5^{\mathrm{a}}$ & $48.9 \pm 6^{\mathrm{a}}$ & $49 \pm 5.6^{\mathrm{a}}$ \\
\hline
\end{tabular}

Each value represents as Mean \pm SD.

a: Significantly different from control

b: Significantly different from EtOH

\subsection{Effect of the FE extract on lipid peroxidation and antioxidant defence systems}

Antioxidant enzymes that can be considered as an indicator of antioxidant activity of $O$. onites infusion in liver, kidney and erythrocyte tissue samples include CAT, SOD, GPx, GST, GR enzyme activities and GSH and MDA levels were determined. According to the results obtained at the end of the experiment the supplementation of rats with the EtOH and alcohol-thyme mixture infusion cause a shift in the antioxidant defence system constituent, MDA content and liver damage biomarker levels in comparison with the rats of control group (Table 2). 
Table 2 Determination of Antioxidant capacity of Origanum onites L. infusion against ethanol exposed rats

\begin{tabular}{|c|c|c|c|c|c|}
\hline & \multirow[b]{2}{*}{ Parameters } & \multicolumn{4}{|c|}{ Groups } \\
\hline & & Group I & Group II & Group III & Group IV \\
\hline \multirow{7}{*}{ 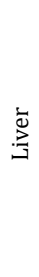 } & GSH (mg/g) & $7.6 \pm 1.2$ & $9.5 \pm 0.6^{\mathrm{a}}$ & $7.40 \pm 0.92$ & $5.6 \pm 1.1^{\mathrm{a}, \mathrm{b}}$ \\
\hline & MDA (nmol/g) & $118.6 \pm 2$ & $144.1 \pm 9^{a}$ & $85.7 \pm 10^{\mathrm{a}}$ & $104.4 \pm 6^{\mathrm{a}, \mathrm{b}}$ \\
\hline & GST (U/g) & $0.76 \pm 0.1$ & $0.80 \pm 0.06$ & $0.722 \pm 0.03$ & $0.45 \pm 0.07^{a, b}$ \\
\hline & GPx (U/g) & $1.4 \pm 0.03$ & $1.51 \pm 0.15$ & $1.54 \pm 0.14^{\mathrm{a}}$ & $1.62 \pm 0.14^{\mathrm{a}}$ \\
\hline & GR (U/g) & $0.04 \pm 0.001$ & $0.04 \pm 0.001$ & $0.03 \pm 0.001^{\mathrm{a}}$ & $0.02 \pm 0.001^{\mathrm{a}, \mathrm{b}}$ \\
\hline & SOD (U/g) & $2229 \pm 28$ & $2233 \pm 33$ & $2169 \pm 62^{\mathrm{a}}$ & $2182 \pm 32^{a, b}$ \\
\hline & CAT (U/g) & $118.8 \pm 3.6$ & $123.7 \pm 7$ & $112.2 \pm 10.8$ & $94.2 \pm 9 \mathrm{a}, \mathrm{b}$ \\
\hline \multirow{7}{*}{ 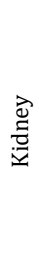 } & GSH (mg/g) & $5.3 \pm 1.02$ & $6.3 \pm 0.9$ & $4.6 \pm 0.8$ & $3.85 \pm 0.7^{\mathrm{a}, \mathrm{b}}$ \\
\hline & MDA (nmol/g) & $99.5 \pm 9.1$ & $124.1 \pm 6^{a}$ & $112.4 \pm 4.4^{\mathrm{a}}$ & $114.7 \pm 7.8^{\mathrm{a}, \mathrm{b}}$ \\
\hline & GST (U/g) & $0.07 \pm 0.01$ & $0.07 \pm 0.01$ & $0.06 \pm 0.001^{\mathrm{a}}$ & $0.06 \pm 0.001^{\mathrm{a}, \mathrm{b}}$ \\
\hline & GPx (U/g) & $8.5 \pm 0.7$ & $12.4 \pm 0.9 \mathrm{a}$ & $7.98 \pm 0.6$ & $10.5 \pm 1.7 \mathrm{a}, \mathrm{b}$ \\
\hline & GR (U/g) & $0.1 \pm 0.01$ & $0.1 \pm 0.001$ & $0.03 \pm 0.001^{\mathrm{a}}$ & $0.04 \pm 0.001^{\mathrm{a}, \mathrm{b}}$ \\
\hline & SOD (U/g) & $2144 \pm 8$ & $2217 \pm 25^{a}$ & $2244 \pm 7$ a & $2242 \pm 8^{a, b}$ \\
\hline & CAT U/g & $62.8 \pm 5.9$ & $69.15 \pm 8.5$ & $52.76 \pm 7.9^{a}$ & $46.4 \pm 4.6^{\mathrm{a}, \mathrm{b}}$ \\
\hline \multirow{7}{*}{ 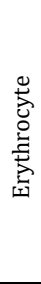 } & $\mathrm{GSH}(\mathrm{mg} / \mathrm{ml})$ & $0.6 \pm 0.04$ & $0.7 \pm 0.10^{\mathrm{a}}$ & $0.9 \pm 0.1^{\mathrm{a}}$ & $0.9 \pm 0.06^{\mathrm{a}, \mathrm{b}}$ \\
\hline & $\mathrm{MDA}(\mathrm{nmol} / \mathrm{ml})$ & $15 . \pm 3.7$ & $18.9 \pm 2.8$ & $6.8 \pm 1.4^{\mathrm{a}}$ & $5.5 \pm 1^{\mathrm{a}, \mathrm{b}}$ \\
\hline & GST $(\mathrm{U} / \mathrm{ml})$ & $0.05 \pm 0.01$ & $0.06 \pm 0.01$ & $0.05 \pm 0.01$ & $0.05 \pm 0.01^{b}$ \\
\hline & $\mathrm{GPx}(\mathrm{U} / \mathrm{ml})$ & $0.85 \pm 0.09$ & $0.94 \pm 0.21$ & $0.68 \pm 0.08^{a}$ & $0.89 \pm 0.15$ \\
\hline & $\mathrm{GR}(\mathrm{U} / \mathrm{ml})$ & $0.01 \pm 0.001$ & $0.01 \pm 0.001$ & $0.01 \pm 0.001^{\mathrm{a}}$ & $0.01 \pm 0.001^{\mathrm{a}, \mathrm{b}}$ \\
\hline & $\operatorname{SOD}(\mathrm{U} / \mathrm{ml})$ & $2294 \pm 4.3$ & $2286 \pm 6^{a}$ & $2286 \pm 4.3^{\mathrm{a}}$ & $2287 \pm 5.3^{\mathrm{a}}$ \\
\hline & CAT $(\mathrm{U} / \mathrm{ml})$ & $105.9 \pm 6.2$ & $109.9 \pm 8.7$ & $92.01 \pm 6.98^{\mathrm{a}}$ & $89.61 \pm 8.04^{a, b}$ \\
\hline
\end{tabular}

Each value represents as Mean \pm SD.

a: Significantly different from control

b: Significantly different from EtOH

\section{Histopathological Findings}

In histopathological examination of the groups rats; microscopically, normal histological appearance of the liver was seen in the NC. Namely, in the group of NC rats, the structures of hepatocytes and portal areas were in normal appearance, and sinusoids in which the hepatocytes formed regular remark cords around the vena centralis and the remark cords were normal (Figure 1). Also, histological appearance of the 0 . onites group rats was similar to the control group. That whereas, almost similar morphological changes were observed in the livers of all rats in the EtOH group. These changes were localized especially in hepatocytes around the portal vein (periportal) of the pins. It was noted that degenerative changes (hydropic degeneration) occurred in the cytoplasm of hepatocytes in these regions. As a result of the degeneration in hepatocytes, the regular remark cord structure of hepatocytes was disrupted and sinusoids were narrowed. It was noted that there was no significant degeneration in hepatocytes around the vena centralist, remark cords and sinusoids had normal appearance (Figure 2). On the other hands, it was observed that morphological changes were very minimal in the alcohol-thyme group, and a view almost similar to the control group was observed (Figure 3).

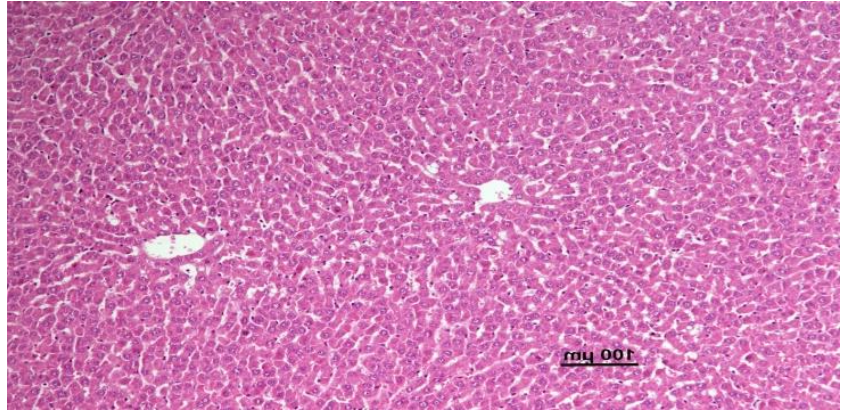

Figure 1 (Control and 0. Onites) : The normal histological appearance of the liver is observed in the control and 0 . onites group.

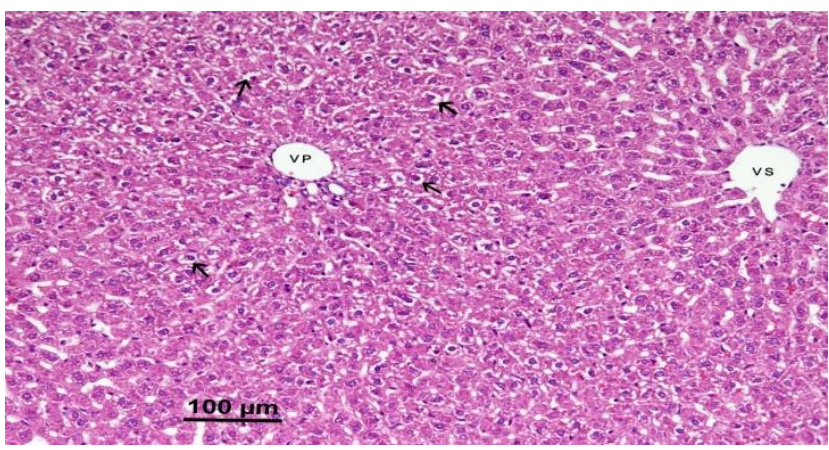

Figure 2 (20\% EtOH): Hydropic degeneration is observed in hepatocytes around the portal vein (VP), and the normal appearance of remark cords and sinusoids around the vena centralist (VS).

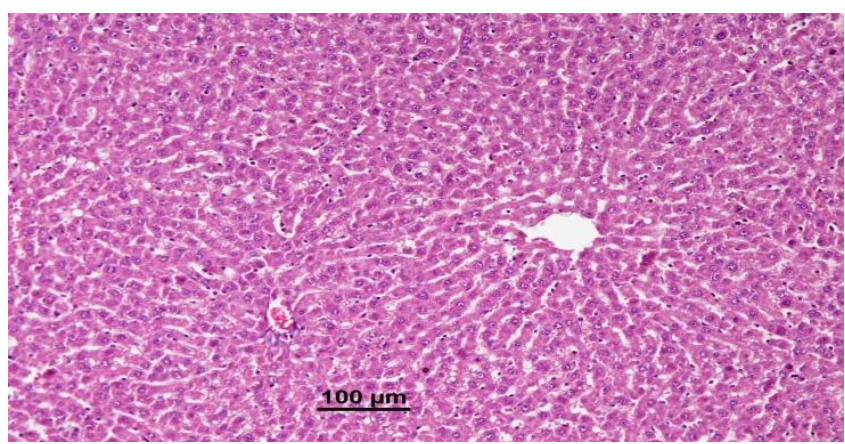

Figure $3(3 \%$ O. onites $+20 \%$ EtOH $)$ : It was observed that morphological changes were very minimal in this group, and a view almost similar to the control group was observed.

\section{Discussion}

It known that one of the sources of free radicals is EtOH and it is reported that excessive EtOH consumption caused damage to liver tissue and many negative metabolic changes, and these adverse effects varied depending on dose and duration, individual strength, diet, and other factors [32]. In addition the rate of ethanol disposed of through the lungs and kidneys is only $2-10 \%$ of the EtOH ingested. The remaining alcohol should be oxidized primarily inside of the organism body liver because it contains the majority of the body's 
enzymes capable of EtOH oxidation. The organ specify to ethanol explain why ethanol metabolism causes such as big imbalances in the liver. So, there has to be attempts to provide protection against these harmful agents and experimental studies have indicated the influence of the functional plant, $O$. onites in this regard. The aim of this study was to investigate whether or not 0 . onites infusion can protect the liver from the toxicity of EtOH, by determination of histopathological changes of liver, serum liver biomarkers level, MDA content and its effectiveness on the antioxidant defence system in rats.

For the first time the results of the present investigation revealed that the treatment of rats with 0 . onites infusion protected the rats from EtOH-induced hepatotoxicity, as is clearly shown by the changes in the levels of serum biomarkers caused by degenerative changes occurred in hepatocytes. In the current study, the rats were feed with EtOH as drinking water for 30 days to induce experimental alcoholises. Hence, the toxicity of ethanol in rats was proved another time. Many studies have revealed the hepatotoxicity of ethanol in a variety of animal species. In addition, EtOH is a peroxidant which is commonly used to produce oxidative stress and experimental liver damage in living organisms $[19,20,22,23,33]$

As summarized in the table 1 and histopathological image examinations (figure 1-3), the current study, while food intake of the all of groups is not change, the fluids consumption of EtOH and alcohol-thyme groups decreased during experimental period compared to that of the control group. The reason for such an effect is not certain but, it can be speculated that the reason behind a significant the decreased consumptions of the rats to EtOH and the alcoholthyme mixtures might have altered their drinking behaviour during experiment. Also, there was a significant increase in the AST and ALT levels of EtOH group in comparison with the control group and a significant decrease in the TP and TC content of EtOH group in comparison to control group. The alcohol-thyme mixture group caused a significant decrease in the AST levels in comparison with the EtOH group whereas, a significant increase in the TP and TC content of alcohol-thyme group in comparison with the EtOH group. The reason behind such an effect of EtOH and O. onites infusion in vivo is not clear to this day. However, the increase in the levels of these enzymes in our study may be the result of changes in the metabolism and detoxification activity of liver as a result of the toxic effects of EtOH. Because, some researchers stated that the liver-derived serum enzyme concentration such as, AST and ALT are both often multiplied in patients with alcoholism [34,35]. It is known that there is a high amount of ALT and AST in hepatocytes and these parameters are sensitive to hepatotoxins and the liver cells damage will discharge their contents such as AST and ALT enzymes into the extracellular space [36]. There is a large amounts of these enzymes in the liver tissues and it is thought that rather than consumption of EtOH they indicate hepatotoxic damage per se. $39-47 \%$ of EtOH-dependent humans has shown elevated AST degrees $[37,38]$. Moreover, the AST to ALT proportion is seen as a valuable parameter for supporting alcoholic hepatitis diagnosis [39-41]. On the other hand, conflicting results in protein synthesis was seen in vivo after chronic administration of ethanol. After a few weeks of administration of a blend of fluid and solid diets containing ethanol a diminished incorporation of labelled amino acids into liver proteins was found in rats nourished the ethanol-containing diets described by researchers [19,42,43]. Furthermore, Morland [19] detected a decrease in the ability of EtOH fed rat liver to corporate amino acids into protein after stimulation with dexamethasone, and reduced activity of enzymes (tyrosine aminotransferase, tryptophan oxygenase) involved in protein metabolism. All of these results and possibilities may clarify the valuable reduction in the total protein level of EtOH group in contrast to the control group in this study. In addition, one of the vital components that control cellular homeostasis and function are lipids. The liver takes a fundamental part in several stages of lipid synthesis, transportation and lipid digestion system. So, it is sensible that those who have extreme liver dysfunction to have an unusual lipid profile (LP). It is known that patients with hepatic failure and serious hepatitis have a noticeable reduction in plasma triglyceride (TG) and cholesterol levels because of a decrease in lipoprotein biosynthesis. In chronic liver diseases, commonly low levels of cholesterol and TG are observed as a result of diminished liver biosynthesis capacity [44]. In our study, a valuable reduction was shown in the total cholesterol level of EtOH group in contrast to the control group. This may have resulted from the changes in lipid homeostasis and liver degeneration induced by ethanol abuse.

EtOH administration in alcoholises studies may elicit severe injury of hepatic cells and architecture as histopathological findings including necrosis in hepatocytes, inflammatory cell infiltration, extensive vacuolization with disappearance of nuclei and impairment in portal area [45]. In present study, similar findings were detected in the EtOH group rats. There were noteworthy reduced of histopathological damages in alcohol-thyme group. According to these results, it was noted that degenerative changes occurred in hepatocytes in the periportal regions of the alcohol group, whereas in the alcohol-thyme group, a normal appearance was observed in the liver. It is understood that this hepatoprotective effect is related to the effect of antioxidant components such as carvacrol and thymol, which are the main factors of the biological activity of oregano that can be found in thyme infusion. The possible cause of degenerative changes in the alcohol group, especially in hepatocytes in the periportal regions, due to the histological structure of the liver, it is believed that hepatocytes in these 
areas are the first to be exposed to toxic components from the digestive tract with vena porta.

As shown in table 2, the current study established that O. onites infusion has antioxidant role in rats. This was evident from the changes in the MDA content of alcohol-thyme group in comparison to the EtOH group. According to the obtained results, EtOH significantly increased MDA contents in the liver, kidney and erythrocyte tissues in comparison to those of control group. On the other hand, the 0 . onites infusion supplemented group's significantly decreased MDA contents in all tissues in comparison to those of $\mathrm{EtOH}$ group. The reason behind such an effect of EtOH and 0 . onites infusion in vivo is not clear to this day. However, the high MDA content is a critical marker of LP and MDA is one of the major oxidation outcomes of peroxidized polyunsaturated fatty acids [46]. Circulating MDA is one of the foremost commonly and broadly utilized oxidative stress biomarkers $[47,48]$. In the current study, the reason for the significant increase in MDA content levels in the EtOH group in comparison to other groups is likely because EtOH administration essentially diminished the antioxidant activities of biological systems and resulted in the aggregation of free radicals which along these lines started lipid peroxidation [49] which in turn increased MDA levels. And the higher levels of hepatic lipid peroxidation may be connected to the fact that the larger part of ethanol metabolism happens within the liver and a vital marker of lipid peroxidation is increased MDA content [50]. Moreover, the bunch by Marnett detailed in 2003 that MDA is mutagenic in human cells [51].

Meanwhile, there were significant fluctuations in the GPx, GR, SOD, GST and CAT activities and GSH levels in the EtOH-treated rats. Nevertheless, the effectiveness of 0 . onites infusion against these fluctuations wasn't determined and to this day the reason behind such effect of the supplemented functional plant is not understood. However, the protective activities of enzymatic antioxidants can be affected by oxidative stress resulted from the exposure of organisms to EtOH. The observed increase in the GSH, SOD and GPx activates may be the result of an adaptive response to ethanol-induced lipid peroxide toxicity [19-21, 23]. Also, the increase in GST enzyme may be was due to the induction of an antioxidant adaptation system. An adaptive change against ethanol-induced lipid peroxide toxicity may be the reason for this increased GST activity [20,22,36]. On the other hands, the reasons for such effect of 0 . onites may be due to the contents of essential oil of oregano, carvacrol and/or thymol as the major constituent(s) and other minor components such as $\mathrm{p}$ cymene, c-terpinene, terpinen-4-ol, linalool, sabinene hydrate, and terpinen-4-ol [15]. Since the major constituent of the essential oil of 0 . onites is the phenolic compound carvacrol, although linalool and thymol chemotypes are observed rarely in wild populations, they may have hepatoprotective and antioxidant effect. Furthermore, it have been repoted that the main component carvacrol has many effect such as cardiac depressant activity, antibacterial, antifungal, lipid peroxidase inhibition, radical scavenging effect, white blood cell macrophage stimulant and acetylcholine esterase inhibition. Carvacrol-rich oils are also recommended for the food preservation due to their antioxidant properties [18].

\section{Conclusion}

The observations made at the end of our research led us to summarize that the subchronic EtOH administration not only leads to a rise in MDA concentration and causes also a shift fluctuated in the antioxidative defence systems, injuries of hepatic cells and increases liver damage biomarkers. However, the supplementation of thyme infusion miht has been provided protective against EtOH induced liver toxicity and oxidative stress.

\section{Acknowledgements}

The authors are grateful to the Van Yüzüncü Yil Üniversity Grant Commission for providing financial assistance during the tenure of research FYL-2018-7283 number. Also, we gratefully thanks to Prof. Dr. Zabit Yener and Dr. Ömer Faruk Keleş for his help in the histopathological section.

\section{References}

[1] Wachtel-Galor, S. and Benzie, I.F., 2011. Herbal medicine: an introduction to its history, usage, regulation, current trends, and research needs. In Herbal Medicine, CRC Press, pp 18-27.

[2] Hartmann, T., 2007. From waste products to ecochemicals: fifty years research of plant secondary metabolism. Phytochemistry, 68, 2831-2846

[3] Jenke-Kodama, H., R. Müller, and E. Dittmann. 2008. Evolutionary mechanisms underlying secondary metabolite diversity. Progress in Drug Research, 6, 121-40.

[4] Li, J.W.H., Vederas J.C., 2009. Drug discovery and natural products: End of an era or an endless frontier. Science, 325, 161-165.

[5] Tonk, F.A., Yüce, S., Bayram, E., Giachino, R.R.A., Sönmez, C.., Telci, I., Furan, M.A., 2010. Chemical and genetic variability of selected Turkish oregano (Origanum onites L.) clones. Plant Systematics and Evolution, 288, 157-165.

[6] Baser, K.H.C., Tumen, G. and Duman, H., 1997. The essential oil of Origanum acutidens (Hand.-Mazz.) Ietswaart. Journal of Essential Oil Research, 9, 91-92.

[7] Tumen, G., Baser, K.H.C., Kirimer, N. and Ozek, T., 1995. Essential oil of Origanum saccatum P.H.Davis. Journal of Essential Oil Research, $7,175-176$

[8] Baser, K.H.C., Tumen, G. and Sezik, E., 1991. The essential oil of Origanum minutiflorum and O. schwarz and P.H.Davis. Journal of Essential Oil Research, 3, 445-446.

[9] Tumen, G., Ermin, N., Ozek, T. and Baser, K.H.C., 1994. Essential oil of Origanum solymicum P.H.Davis. Journal of Essential Oil Research, $6,503-504$. 
[10] Tumen, G. and Baser. K.H.C. (1993). The essential oil of Origanum syriacum L. var. bevanii (Holmes) Ietswaart. Journal of Essential Oil Research, 5, 315-316.

[11] Baser, K.H.C., Ozek, T., Kurkcuoglu, M. and Tumen, G., 1994. The essential oil of Origanum vulgare subsp. hirtum of Turkish origin. Journal of Essential Oil Research, 6, 31-36.

[12] Sezik, E., Tumen, G., Kirimer, N., Ozek, T. and Baser, K.H.C., 1993. Essential oil composition of four Origanum vulgare subspecies of Anatolian origin. Journal of Essential Oil Research, 5, 425-431.

[13] Baser, K.H.C., Ozek, T. and Tumen, G., 1995. Essential oil of Origanum rotundifolium Boiss. Journal of Essential Oil Research, 7, 95-96.

[14] Ceylan, A., Bayram, E. and Geren, H., 1999. Investigation on agronomical and quality characteristics of improved clonnes in Origanum (Origanum onites L.) breeding. Turkish Journal of Agriculture and Forestry, 23, 1163-1168.

[15] d'Antuono, L.F., Galletti, G.C., Bocchini, P., 2000. Variability of essential oil content and composition of Origanum vulgare $\mathrm{L}$. populations from a North Mediterranean Area (Liguria Region, Northern Italy). Annals of Botany, 86, 471-478.

[16] Baser, K.H.C., 2002. Aromatic biodiversity among the flowering plant taxa of Turkey. Pure Applied Chemistry, 74, 527-545.

[17] Kokkini, S., 2004. Essential oil composition of Greek (Origanum vulgare ssp. hirtum) and Turkish (O. onites) oregano: A Tool for Their Distinction. Journal of Essential Oil Research, 5, 71-77.

[18] Kirimer, N., Başer, K.H.C., Tümen, G., 1995. Carvacrol-rich plants in Turkey. Chemistry of Natural Compounds, 31, 37-41.

[19] Aykaç G, Uysal M, Suha Yalcin A, 1985. The effect of chronic ethanol ingestion on hepatic lipid peroxide, glutathione, glutathione peroxidase and glutathione transferase in rats. Toxicology, 36, 71-76.

[19] Mørland, J., Sjetnan, A.E., 1976. Effect of ethanol intake on the incorporation of labelled amino acids into liver protein. Biochemical Pharmacology, 25, 2125-2130.

[20] Sonde, V., D'souza, A., Tarapore, R., Pereira, L., Khare, M.P., Sinkar, P., Krishnan, S., Rao, C.V., 2000. Simultaneous administration of diethylphthalate and ethyl alcohol and its toxicity in male SpragueDawley rats. Toxicology, 147, 23-31.

[21] Celik, I., Temur, A. and Isik, I., 2009. Hepatoprotective role and antioxidant capacity of pomegranate (Punica granatum) flowers infusion against trichloroacetic acid-exposed in rats. Food and Chemical Toxicology, 47, 145-149.

[22] Yurt B, Celik I (2011) Hepatoprotective effect and antioxidant role of sun, sulphited-dried apricot (Prunus armeniaca L.) and its kernel against ethanol-induced oxidative stress in rats. Food and Chemical Toxicology, 49, 508-513.

[23] Dogan, A., Celik, I., 2012. Hepatoprotective and antioxidant activities of grapeseeds against ethanol-induced oxidative stress in rats. British Journal of Nutrition, 107, 45-51.

[24] Jain, S. K., McVie, R., Duett, J. 1989. Erythrocyte membrane lipid peroxidation and glycosylated hemoglobin in diabetes. Diabetes, 38, $1539-1543$

[25] Beutler, E., Duron, O., Kelly, B.M., 1963. Improved method for the determination of blood glutathione. Journal of Laboratory and Clinical Medicine, 61, 882-888.

[26] Mannervik, B., Guthenberg, C., 1981. Glutathione transferase (human placenta). In Methods in Enzymology. Academic Press, 77, 231-235.
[27] Carlberg, I.N.C.E.R. and Mannervik, B.E.N.G.T., 1975. Purification and characterization of the flavoenzyme glutathione reductase from rat liver. Journal of biological chemistry, 250, 5475-5480.

[28] Paglia, D. E., Valentine, W. N., 1967. Studies on quantitative and qualitative characterization of erythrocyte glutathione peroxidase. Journal of Laboratory and Clinical Medicine, 70, 158.

[29] McCord, J.M., Fridovich, I., 1969. Superoxide dismutase, Journal of Biological Chemistry, 244, 6049-6055.

[30] Aebi, H., 1974. Catalase, In Methods of Enzymatic Analysis (Bergemeyer, H U.,ed) Academic Press, New York-London. 673-684.

[31] Demir, R., 2001. Histolojik Boyama Teknikleri. Palme Yayıncılık, 1st ed., Ankara, Turkey. pp. 51-61.

[32] Murray R. K., Granner D. K., Mayes P. A., Radwell V. W. 1988. Harper's Biochemistry. 21th ed., Long Medical Book, London. pp. 5783.

[33] Kolankaya, D., Selmanoğlu, G., Sorkun, K., Salih, B., 2002. Protective effects of Turkish propolis on alcohol-induced serum lipid changes and liver injury in male rats. Food Chemistry, 78, 213-217.

[34] Rosman, A.S., Lieber, C.S., 1994. Diagnostic utility of laboratory tests in alcoholic liver disease. Clinical Chemistry, 40, 1641-1651.

[35] Niemelä, 0., 2002. Serum diagnosis of alcoholic liver disease and markers of ethanol intake. Ethanol and the Liver, 411-449.

[36] Yayalacı, Y., Celik, I., Batı, B., 2014. Hepatoprotective and antioxidant activity of linden (Tilia platyphyllos L.) infusion against ethanol-induced oxidative stress in rats. The Journal of Membrane Biology, 247, 181-188.

[37] Helander, A., Tabakoff, B., Centres, W.I.S., 1997. Biochemical markers of alcohol use and abuse: experiences from the pilot study of the WHO/ISBRA collaborative project on state and trait markers of alcohol. Alcohol and Alcoholism, 32, 133-144.

[38] Hietala, J., Koivisto, H., Anttila, P., Niemelä, O., 2006. Comparison of the combined marker GGT-CDT and the conventional laboratory markers of alcohol abuse in heavy drinkers, moderate drinkers and abstainers. Alcohol and Alcoholism, 41, 528-533.

[39] Finlayson, N.D.C., 1993. Clinical features of alcoholic liver disease. Baillière's Clinical Gastroenterology, 7, 627-640.

[40] Harrison, D.J., Burt, A.D., 1993. Pathology of alcoholic liver disease. Baillière's Clinical Gastroenterology, 7, 641-662.

[41] Bacon, B.R., Farahvash, M.J., Janney, C.G., Neuschwander-Tetri, B.A., 1994. Nonalcoholic steatohepatitis: an expanded clinical entity. Gastroenterology, 107, 1103-1109.

[42] Porta, E.A., Koch, O.R., Gomez-Dumm, C.L., Hartroft, W.S., 1968. Effects of dietary protein on the liver of rats in experimental chronic alcoholism. The Journal of Nutrition, 94, 437-446.

[43] Mørland, J., 1974. Effect of chronic ethanol treatment on tryptophan oxygenase, tyrosine aminotrans-ferase and general protein metabolism in the intact and perfused rat liver. Biochemical Pharmacology, 23, 21-35.

[44] Halsted, C.H., 2004. Nutrition and alcoholic liver disease. In Seminars in Liver Disease, 24, 289-304.

[45] Turan, A., Celik, I., 2016. Antioxidant and hepatoprotective properties of dried fig against oxidative stress and hepatotoxicity in rats. International Journal of Biological Macromolecules, 91, 554-559.

[46] Freeman, B.A., Crapo, J.D., 1981. Hyperoxia increases oxygen radical production in rat lungs and lung mitochondria. Journal of Biological Chemistry, 256, 10986-10992. 
[47] Draper, H.H., Hadley, M., 1990. (43) Malondialdehyde determination as index of lipid Peroxidation. Methods in Enzymology, 186, 421-431.

[48] Giustarini, D., Dalle-Donne, I., Tsikas, D., Rossi, R., 2009. Oxidative stress and human diseases: origin, link, measurement, mechanisms, and biomarkers. Critical Reviews in Clinical Laboratory Sciences, 46, 241-281.

[49] Wang, M., Zhu, P., Jiang, C., Ma, L., Zhang, Z., Zeng, X., 2012. Preliminary characterization, antioxidant activity in vitro and hepatoprotective effect on acute alcohol-induced liver injury in mice of polysaccharides from the peduncles of Hovenia dulcis. Food and Chemical Toxicology, 50, 2964-2970.
[50] Molina, M.F., Sanchez-Reus, I., Iglesias, I., Benedi, J., 2003. Quercetin, a flavonoid antioxidant, prevents and protects against ethanol-induced oxidative stress in mouse liver. Biological and Pharmaceutical Bulletin, 26, 1398-1402.

[51] Niedernhofer, L.J., Daniels, J.S., Rouzer, C.A., Greene, R.E., Marnett, L.J., 2003. Malondialdehyde, a product of lipid peroxidation, is mutagenic in human cells. Journal of Biological Chemistry, 278, 31426-31433.

[52] Halliwell, B., Gutteridge, J.M., 2015. Free Radicals in Biology and Medicine, Oxford University Press, USA. 